\title{
PIPELINES CATHODIC PROTECTION DESIGN METHODOLOGIES FOR IMPRESSED CURRENT AND SACRIFICIAL ANODE SYSTEMS
}

\author{
E. S. Ameh ${ }^{1, *}$ and S. C. Ikpeseni ${ }^{2}$

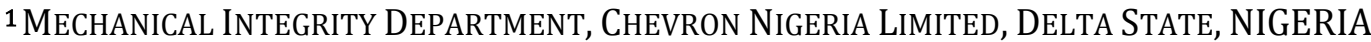 \\ 2 Department of Mechanical EngineEring, Delta State University, Oleh Campus, Delta State, NiGERIA \\ E-mail addresses: ${ }^{1}$ stanley.ameh@yahoo.com, ${ }^{2}$ sunnychukwuyem@yahoo.com
}

\begin{abstract}
Several inadequate designs of cathodically polarized offshore and onshore pipelines have been reported in Nigeria owing to design complexity and application of the cathodic protection system. The present study focused on critical and detailed approach in impressed current and sacrificial anode design calculation methodologies for $0.5 \mathrm{~m}$ diameter and $100000 \mathrm{~m}$ length of X65 steel pipeline in onshore and $1.2 \mathrm{~m}$ diameter and $120000 \mathrm{~m}$ length of X42 steel pipeline in offshore of Niger Delta region of Nigeria. The impressed current design calculation showed 2592150mA of current demand and voltage of $1127585 \mathrm{mV}$ required to adequately protect the X65 pipeline with external surface area of $86405 \mathrm{~m}^{2}$. The current and voltage requirements were achievable by installing six transformer rectifiers with minimum direct current output of 500amperes and direct voltage output of 200volts. But the sacrificial anode design calculation indicated direct current output of $2262240 \mathrm{~mA}$ was needed to marginally polarize the X42 pipeline with total external surface area of $226224 \mathrm{~m}^{2}$. The computation further showed the current requirement was attainable with connection of 3620 anodes to set up a natural potential between sacrificial anode and pipeline.
\end{abstract}

Key words: Cathodic protection, corrosion, impressed current, pipeline, sacrificial anodes

\section{INTRODUCTION}

In the world today, pipelines are being used as means of conveying hydrocarbon from wellheads to production facilities, storage tanks and distribution of the refined product to towns and cities. Steel pipeline is widely used because it is the most cost effective and safest means of transporting hydrocarbon and other derivatives. However, one of the challenges being faced in the oil and gas industry is corrosion attack on process facilities. Koch, et al [1] revealed direct cost of oil and gas pipelines corrosion in the United State of American alone was estimated to be $\$ 7$ billion US dollars. Several pipelines failures due to external corrosion is on the rise owing to exposure to corrosive environment after coating failures. The adverse effect of pipeline failures due to corrosion include high cost of cathodic protection system maintenance, plants shutdown, environmental pollution, production losses, fatalities and injuries where unintentional released of hydrocarbon finds ignition source [2].

Cathodic protection is an electrical method of control or preventing external corrosion of pipeline steels and other metallic structures buried in soil or submerged in water [3]. The practical application of cathodic protection was first used by Davy Humphrey to prevent sheet of copper cladding used as the hull of naval vessel from corroding by connecting small quantity of zinc or iron to the sheet of copper. The technique has since become an accepted method of protecting structures from corroding [4]. The cathodic protection principle is based on reversibility of electron flow to prevent current leaving the corroding area or moving the equilibrium potential of the structure to be protected to a more electron negative value (lower potential) and supply external source of current to flow into the structure [5]. The principle of cathodic protection can be explained with electrochemical reactions. In corrosion of iron, the metal ion enters solution at the anodic areas in a quantity equals to cathodic reactions and flow to the cathodic areas so that electrons on both sides are balanced. The anodic and cathodic reactions are givens as:

At the anodic areas, atoms of metal release electron to become metal ions as shown [6]:

\footnotetext{
* Corresponding author tel: +234-812-721-6307
} 


$$
2 M \rightarrow 2 M^{+}+2 e^{-}
$$

In (1), $M$ is the metal atom, $M^{+}$is the metal ion and $e^{-}$ is electron.

A general reaction at the anode where iron is corroding in non-acidic environment such as water or soil electrolyte is represented as:

$$
F \rightarrow F^{2+}+2 e^{-}
$$

The reaction released free electron that remains in the structure of the metal and the metal ions move away from the metal structure and enter the environment where it is consumed at the cathodic area.

At cathodic area in acidic solution in the presence of water, the reaction is represented as [7]:

$$
2 \mathrm{H}^{+}+2 e^{-} \rightarrow \mathrm{H}_{2}
$$

Equation (3) reaction produced two hydrogen ions to form two atoms of hydrogen. Another possible cathodic reaction in aerated water or soil that is non-acidic where oxygen is dissolved in a solution and consumed but still corrosion occur at the anode and not at the cathodic is represented as:

$$
\mathrm{O}_{2}+2 \mathrm{H}_{2} \mathrm{O}+4 e^{-} \rightarrow 4 \mathrm{OH}^{-}
$$

The whole of equations (2) to (4) which are electrochemical reactions that occur during corrosion process can be summarized into one equation as shown:

$$
2 \mathrm{Fe}+2 \mathrm{H}_{2} \mathrm{O}+\mathrm{O}_{2} \rightarrow 2 \mathrm{Fe}(\mathrm{OH})_{2}
$$

Cathodic protection techniques are widely used in protection of offshore and onshore oil production facilities such as buried and submerged pipelines, subsea manifolds, jackets, tanks as well as marine and major port facilities [8]. Protection potential range has been established and recommended to ensure pipelines and other related structures are adequately protected. To protect pipelines in soil environment, constant potential between -0.85 volts and -1.20 volts with referenced to saturated copper/copper sulfate electrode is maintained while in seawater or neutral environment, a potential between -0.80 volts and -1.10 volts is constantly maintained with referenced to silver/silver chloride electrode and there are basically two techniques of applying cathodic protection to protect structures, namely sacrificial anode and impressed current techniques[9].

Sacrificial anode cathodic protection system involves connection of a more negative electrochemical metallic anode with the intended structure to be protected via a wire to complete the circuit. The method of protection requires no external power source but based on the natural potential existing between sacrificial anode and protected structure. For sacrificial anode system, the metallic anode dissolves, get consumed gradually and the current flow from the anode through the soil (electrolyte) down to the protected structure because of natural potential difference between the protected structure and the metallic anode [10]. Metallic anodes commonly used in the protection of steel structures are magnesium, zinc and aluminum and their selection depends largely on electrolyte conductivity or resistivity. Thus, magnesium is most suitable in seawater; aluminum in freshwater but zinc can be used in both seawater and land [11]. It is less expensive to install, lower maintenance cost and the current distribution to the intended structure is quite uniform and therefore pose no risk of overprotection and potential coating damage. However, the current output delivery is small compared to impressed current system, so it is only effective for smaller structure. One other obvious disadvantage of the protection system is that the sacrificial anode gradually gets consumed, thus needing replacement after depletion [12].

Impressed current cathodic protection system uses highly energized (inert) anodes such as silicon cast iron, graphite, platinum clad, silicon mixed metal oxide and niobium coated wire which are then connected to positive terminal of the power source (rectifier) and to the anode while structure intended to be protected is connected to the power source negative terminal. The original power source which is alternative current is converted to direct current by a rectifier [3]. The inert anode for the impressed current system remained undissolved and non-consumed throughout the protection period but in the process the inert anode causes hydrogen gas evolution reaction at the anodic region. For structures' potential to be lowered or cathodically protected, the structures must be in contact with power source and in electrolytic environment [13]. The impressed current cathodic protection system delivers adequate power output and therefore used for protection of larger structures and several kilometers of pipelines. Above all, the inert anodes are not consumed, hence requires no replacement. But the current distribution is usually not uniform leading to overprotection and coating damages of structures that are in closed proximity to the power source if not insulated [14]. It has become necessary to critically evaluate design processes of cathodic protection system due to rising corrosion and increasing pipelines construction and installation in very harsh environment owing to remote oil and gas exploitation and exploration. Therefore, the aim of the research work was to simplify design complexity in a step-by-step approach and detailed methodologies involved in cathodic protection design with a view to broadening the understanding and optimizing design. 
Several new and old networks of pipelines in the world now are without cathodic protection system and with high risk of pipelines external corrosion that can be controlled and life span extended with installation of adequately designed cathodic protection system.

\section{DESIGN METHODOLOGIES}

\subsection{Materials and Impressed Current Design}

Carbon steel pipeline of $0.5 \mathrm{~m}$ diameter and $100000 \mathrm{~m}$ length was to be laid in onshore location in Niger Delta region spanning from Delta to Bayelsa State in Nigeria. Impressed current cathodic protection system was designed for installation. The basis of design parameters for pipeline, anode and environment studied are provided in Table 1, 2 and 3 respectively.

Table 1:Pipeline data

\begin{tabular}{ll}
\hline Pipeline grade & $\mathrm{X} 65$ \\
\hline Diameter & $0.5 \mathrm{~m}$ \\
Length & $100000 \mathrm{~m}$ \\
Coating resistance & $18 \Omega \cdot \mathrm{m}^{2}$ \\
Assumed coating efficiency & $55 \%(0.55)$ \\
Design life & 35 years \\
Pipe joint length & $4 \mathrm{~m}$ \\
\hline
\end{tabular}

Table 2: Anode data

\begin{tabular}{ll}
\hline Anode material & Platinum clad \\
\hline Current density & $30 \mathrm{~mA} / \mathrm{m}^{2}$ \\
Design life & 35 years \\
Anode dimension & $0.75 \mathrm{~m} \mathrm{x} 0.75 \mathrm{~m} \mathrm{x}$ \\
Utilization of platinum clad & $3.00 \mathrm{~m}$ \\
Weight of anode & $65 \% \mathrm{~kg} / \mathrm{amp}-\mathrm{yr}$ \\
Backfill length surrounding & $30 \mathrm{~kg}$ \\
anode & $0.5 \mathrm{~m}$ \\
Backfill diameter surrounding & \\
anode & $0.15 \mathrm{~m}$ \\
Cable wire specification & 0.0212 ohms per \\
& $100 \mathrm{ft}$ \\
\hline
\end{tabular}

Table 3: Soil resistivity

\begin{tabular}{ll}
\hline Distance $(\mathrm{m})$ & Resistivity $(\Omega . \mathrm{m})$ \\
\hline 0 & 50 \\
10000 & 45 \\
20000 & 50 \\
30000 & 52 \\
40000 & 60 \\
50000 & 65 \\
60000 & 70 \\
70000 & 75 \\
80000 & 74 \\
90000 & 80 \\
100000 & 62 \\
\hline
\end{tabular}

Design of the impressed current cathodic protection system was carried out based on the preliminary field information provided in Tables 1 to 3 . The procedure for the design involved the following sequence starting with current demand being the current required to cathodically protect the pipeline under consideration or change the structure potential to minimum value of 0.85 volts. The current requirement depends on coating quality, soil resistivity along the right of way and total external surface area of the pipeline. The current requirement $\left(I_{r}\right)$ was established using the following formula [9]:

$$
I_{r}=S_{a} I_{c}
$$

where, $I_{c}$ is the current density, $S_{a}$ is the total external surface area and $f_{c}$ is the coating efficiency based on field experience. The total external surface area of the pipeline is estimated as:

$$
S_{a}=\pi D L f_{c}
$$

$$
S_{a}=3.142 \times 0.5 \times 100000 \times 0.55=86405 \mathrm{~m}^{2}
$$

then, $I_{r}=86405 \times 30=2592150 \mathrm{~mA}$

Next step was computation of required number of anodes needed to meet current density limitation specified by the manufacturer:

$$
N_{a}=\frac{I_{r}}{A_{a} I_{c}}
$$

In (8), $I_{r}$ is the total current required to protect the pipeline, $N_{a}$ is the required number of anodes and $A_{a}$ is the anode surface area estimated as:

$$
A_{a}=\pi d l=3.142 \times 0.75 \times 3=7.1 \mathrm{~m}^{2}
$$

$N_{a}=\frac{2592150}{7.1 \times 30}=12170$ anodes

Then required number of anodes needed to meet 35 years intended design life based on the required current was calculated using the following formula [15]:

$$
N_{a}=\frac{d_{l} I_{r}}{1000 W}
$$

In (10), $d_{l}$ is the design life and $W$ is the anode weight

$$
\therefore N_{a}=\frac{35 \times 2592150}{1000 \times 30}=3024 \text { anodes }
$$

Additionally, anode spacing is an important design parameter that is used to ensure maximum allowable voltage drop is not exceeded. The anode spacing can be lowered if allowable voltage drop is exceeded by choosing anode with lower weight or increasing the number of anodes. The anode spacing $\left(A_{s}\right)$ is estimated with equation (11):

$$
A_{s}=\frac{\text { pipeline lenght }}{N_{a}}=\frac{100000}{3024}=33 \mathrm{~m}
$$

Next is calculation of interval of pipe joint to determine interval of anode bracelet that will be placed. The interval of pipe joint is given as: 


$$
\begin{gathered}
\text { Interval }=\frac{A_{s}}{\begin{array}{c}
\text { Average lenght of pipe joint } \\
=8.25 \text { joint }
\end{array}}=\frac{33}{4} \\
\text {. }
\end{gathered}
$$

Furthermore, anode to electrolyte resistance known as resistance to earth remains a critical parameter in cathodic protection system design evaluation in predicting anode current output. The other resistances include structure to electrolyte and cabling resistance and are often neglected in design for offshore location. The resistance to earth of a single vertical anode was computed using the mathematical expression [16]:

$$
R_{V}=0.00512 \rho \frac{\left[\operatorname{In}\left(8 A_{l} / A_{d}\right)-1\right]}{A_{l}}
$$

where, $R_{V}$ is the resistance to earth of vertical anode, $A_{l}$ is the anode length plus backfill, $A_{d}$ is the anode diameter plus backfill and $\rho$ is the average soil resistivity taken as $62 \Omega . m$ as against taking the lowest value since there was no significant variations of the values.

$$
\begin{aligned}
R_{V}=0.0052 \times 62 & \frac{[\operatorname{In}(8\{3+0.5\} /\{0.75+0.15\})-1]}{\{3+0.5\}} \\
& =0.22 \mathrm{ohms}
\end{aligned}
$$

Anode lead wire cable was supplied in ohms per $100 \mathrm{ft}$ per manufacturer's specification and the cable wire resistance $\left(R_{w}\right)$ was computed with equation (14):

$$
R_{w}=\frac{o h m s L}{100 f t}
$$

where, $L$ is the length of structure(pipeline) measured in $\mathrm{ft}$.

$$
\therefore R_{w}=\frac{0.0212 \times 328 \mathrm{ft}}{100 \mathrm{ft}}=0.070 \mathrm{ohms}
$$

Next is the structure to electrolyte $\left(R_{c}\right)$ computation using equation (15):

$$
R_{c}=\frac{R}{A_{c}}
$$

where, $R$ is the coating resistance and $A_{c}$ is the area of the coated pipeline surface. The entire pipeline length under consideration has been coated. So, $A_{c}=S_{a}$.

$$
\therefore R_{c}=\frac{18}{86405}=0.0002 \mathrm{ohms}
$$

Next step was computation of total circuit resistance $\left(R_{T}\right)$ needed to estimate size of rectifier needed in terms of voltage output. The determination of total resistance was estimated with simple mathematical expression [17] as:

$$
\begin{gathered}
R_{T}=R_{V}+R_{w}+R_{c} \\
R_{T}=0.22+0.070+0.0002=0.290 \mathrm{ohms}
\end{gathered}
$$

Furthermore, rectifiers were sized and selected to meet current requirement and voltage output. The voltage requirement was calculated with equation (17):

$$
V_{r}=I_{r} R_{T} 150 \%
$$

where, $V_{r}=$ voltage output requirement and the $150 \%$ represent factor built in to accommodate rectifier ageing to ensure delivery not below the needed voltage output.

$$
V_{r}=\frac{2592150 \times 0.290 \times 150}{100}=1127585 \mathrm{mV}
$$

\subsection{Materials and Sacrificial Anode Design}

Sacrificial anode cathodic protection design was performed for $1.2 \mathrm{~m}$ diameter export pipeline in offshore location ranging from 50 to $100 \mathrm{~m}$ depth. The design basis for the pipeline data and anode properties studied are given in Table 4 and 5 respectively. Resistivity of seawater and mud on the right of way of the pipeline were given as $0.3 \Omega . \mathrm{m}$ and $4.0 \Omega . \mathrm{m}$ respectively.

Table 4: Pipeline data

\begin{tabular}{ll}
\hline Pipeline material grade & $\mathrm{X} 42$ \\
\hline Diameter & $1.2 \mathrm{~m}$ \\
Pipeline length in seawater and & $120000 \mathrm{~m}$ \\
mud & $80000 \mathrm{~m}$ \\
Length in seawater & $40000 \mathrm{~m}$ \\
Length buried in mud & $10 \mathrm{~mA} / \mathrm{m}^{2}$ \\
Average current density in & $30 \mathrm{~mA} / \mathrm{m}^{2}$ \\
seawater & 0.5 \\
Average current density in mud & 40 years \\
Coating efficiency & $3 \mathrm{~m}$ \\
Design life & \\
Pipe joint length & \\
\hline
\end{tabular}

Table 5:Anode properties

\begin{tabular}{ll}
\hline Anode material & Mg alloy \\
\hline Current density & $25 \mathrm{~mA} / \mathrm{m}^{2}$ \\
Dimension & $0.67 \mathrm{x} 0.67 \times 3.5 \mathrm{~m}$ \\
Mg alloy consumption rate & $4 \mathrm{~kg} / \mathrm{amp}-\mathrm{yr}$ \\
Potential with ref to $\mathrm{CuSO}_{4}$ & $-1.55 \mathrm{volts}$ \\
Electrochemical capacity of & $1230 \mathrm{Amp}-\mathrm{hr} / \mathrm{kg}$ \\
Anode & $25 \mathrm{~kg}$ \\
Weight of anode & 0.85 \\
Utilization & \\
\hline
\end{tabular}

Magnesium driving potential volt with referenced to copper/copper sulfate was given as -1.55 volts. From practical field experience, average potential volt of uncoated steel pipeline in seawater with referenced to copper/copper sulfate usually reads -0.68 volts. Therefore, net initial driving potential between sacrificial anode and cathode was estimated [18] using equation (18):

$$
E=E_{a}-E_{c}
$$

where, $E=$ net initial driving potential, $E_{a}=$ anode driving potential and $E_{c}=$ average steel pipeline potential.

$$
E=-1.55-(-0.68)=-0.87 \text { volt }
$$

Since pipeline will be cathodically polarized to minimum of $-0.85 \mathrm{volt}$ with reference to 
copper/copper sulfate, net final driving potential can be estimated as:

$$
E=-1.55-(-0.85)=-0.7 \text { volt }
$$

Next step was to compute total external surface area of the pipeline to be protected using equation (7):

$$
S_{a}=3.142 \times 1.2 \times 120000 \times 0.5=226224 m^{2}
$$

Resistivity deference between mud and seawater provided in section 2.2 appeared very significant. Therefore, the lowest resistivity value of $0.3 \Omega \mathrm{m}$ would be used instead of the average value since decreasing resistivity increases corrosion rate which implied the corresponding current density would be used in the computation of current requirement for sacrificial anode design using equation (6):

$$
I_{r}=226224 \times 10=2262240 \mathrm{~mA}
$$

Resistance to earth for sacrificial anode cathodic protection system was calculated using equation (13):

$$
R_{V}=0.00512 \times 0.3 \frac{[\operatorname{In}(\{8 \times 3.5\} /\{0.67\})-1]}{3.5}=0.78 \Omega
$$

Next was estimation of current output per anode $\left(I_{a}\right)$ obtained using the equation (19):

$$
I_{a}=\frac{E}{R_{V}}=\frac{0.85}{0.78}=1.1 \mathrm{~A}
$$

Design life of individual anode can be estimated using the following formula[19]:

$$
d_{a}=\frac{M u \varepsilon}{I_{a} 8760}
$$

where, $d_{a}=$ design life of individual anode, $u=$ utilization factor, $\varepsilon=$ electrochemical capacity of anode and $M=$ total net weight of sacrificial anode needed to protect the pipeline was given as:

$$
\begin{aligned}
& M=\frac{I_{c} d_{l} 8760}{u \varepsilon}=\frac{25 \times 40 \times 8760}{0.85 \times 1230}=8379 \mathrm{~kg} \\
& \therefore d_{a}=\frac{8379 \times 0.85 \times 1230}{1.1 \times 8760}=909 \mathrm{hrs}=0.1 \mathrm{year}
\end{aligned}
$$

Next step involves computing number of anodes needed to meet intended design life of pipeline using equation (10):

$$
N_{a}=\frac{40 \times 2262240}{1000 \times 25}=3620 \text { anodes }
$$

This was followed by estimation of anode spacing to determine linear distance of anode arrangement and it is computed with equation (11):

$$
A_{s}=\frac{120000}{3620}=33.2 \mathrm{~m}
$$

Following anode spacing estimation is interval of pipe joint estimation using equation (12):

$$
\text { Interval }=\frac{33.2}{3}=11 \text { joint }
$$

Finally, ground bed selection which represent location prepared to keep either single or combination of anodes is most time the final phase of design and preparation. Prior to this last phase, protection area for each anode $P_{a}$ requires estimation using the following expression:

$$
P_{a}=\frac{S_{a}}{N_{a}}=\frac{226224}{3620}=62.5 \mathrm{~m}^{2}
$$

\section{DISCUSSIONS}

Impressed current and sacrificial anode cathodic protection current demands of the onshore X65 steel pipeline with $0.5 \mathrm{~m}$ diameter and $100000 \mathrm{~m}$ length, and the offshore X42 steel pipeline with $1.2 \mathrm{~m}$ diameter and $120000 \mathrm{~m}$ length have been computed according to equation (1). The impressed current and sacrificial anode direct current demands were calculated as $2592150 \mathrm{~mA}$ and $2262240 \mathrm{~mA}$ respectively based on coating deficiency and external surface areas. On the other hand, the quantity of platinum clad anodes needed to deliver the direct current demand output of $2592150 \mathrm{~mA}$ was estimated as 12170 anodes while 3024 anodes are required to meet 35 years intended design life of the onshore pipeline. For the sacrificial anode, design calculation showed current requirement was attainable with connection of 3620 magnesium alloy anodes to set up a natural potential that will meet 40 years intended design life of the offshore pipeline before the anodes get completely consumed. According to Bradford [12], anodes of sacrificial anode protection technique get gradually consumed thus needing replacement after depletion if the candidate pipeline is still in service or not retired. Furthermore, the impressed current design calculation showed output voltage of $1127585 \mathrm{mV}$ was required to adequately protect the onshore pipeline external surface area of $86405 \mathrm{~m}^{2}$. Hence, rectifiers selection and quantity needed to be installed on the entire pipeline to meet the voltage requirement was evaluated and the voltage requirement was achievable with six transformers rectifiers with minimum of current output of 500amper and direct voltage output of 200volts.

From the calculation of initial driving potential of 0.87 volts, the design indicated the onshore and offshore pipelines are within protection range. This value agrees with DNV [9] that constant potential between -0.85 volts and -1.2 volts with reference to saturated copper/copper sulfate electrode or potential between -0.80 volts and -1.1 volts with reference to silver/silver chloride electrode guaranty pipelines protection. The impressed current and sacrificial anode design provided estimate of current requirement to allow comparison of the external current flow to protect the pipelines. This implied that if the values of current requirements fall below the calculated 
threshold, the voltage requirement will be less than adequate and the pipelines will not be marginally polarized. Therefore, any pipeline parts directly exposed to corrosive environment will be susceptible to external corrosion when there are coating failures. For the onshore and offshore pipelines to be cathodically polarized, the supplied current outputs were designed to be more than adequate in line with Bushman [3] that cathodic protection system prevent external corrosion only if the supplied current flowing to structures are above the demand current of the environment.

\section{CONCLUSIONS}

Cathodic protection design of the impressed current showed current demand of $2592150 \mathrm{~mA}, 3024$ platinum clad anodes required to attain 35 years' design life and $1127585 \mathrm{mV}$ voltage output required to adequately protect $\mathrm{X} 65$ steel pipeline to be laid in offshore location. The cathodic protection design calculation of the sacrificial anode for the X42 steel pipeline to be laid in onshore showed total current demand of $2262240 \mathrm{~mA}$ was required to protect the pipeline. The design further indicated 3620 magnesium alloy anodes are needed to set up a natural potential between anode and the pipeline to attain the current demand. The cathodic protection design calculation methodologies adopted a step-by-step approach thus would provide valuable insight and guide corrosion engineers in designing cathodic protection system for pipelines.

\section{REFERENCES}

[1] Koch, G. Brongers, M. Thompson, N. Virmani, Y. and Payer, J. "Corrosion Cost and Preventive Strategies in the United State, USA: FHWA Report, RO-01-15, 2001.

[2] NACE, "Control of External Corrosion of Underground or Submerged Metallic Piping System", 2007.

[3] Bushman, J.B. "Corrosion and Cathodic Protection Theory", Bushman Association lnc, Medina, Ohio, 2012.

[4] Humphrey, S. D. "Recollection Development of the Mind and Character", Trans, Royal society, pp 114-242, 1824.
[5] Talbot, D. and Talbot, J. "Corrosion Science and Technology", CRC and LLC Press, New York, 1998.

[6] Wald, S. R. F.“Corrosion”, NACE, P.I, 1968.

[7] Roberge, P. R. "Handbook of corrosion Engineering", McGraw- Hill PY, New York, 2000.

[8] Parker, M.E. and Peattie, E.G. "Pipeline corrosion and Cathodic Protection", Houston Texas, Gulf Professional Publishing, 1997.

[9] DNV, "Cathodic Protection Design", Recommended Practice RP, DVN Corporate Headquarter, Oslo, Norway, 1993.

[10] Ashworth, V. "Principle of Cathodic", Third Edition, Vol. 2, , pp 2-27, 2010.

[11] Mainier, F. B., Leta, F. R. and Feliciano, F. F. "Application of Anti-corrosive Techniques Compatible with the Environment to Engineering Education", American Journal of Environmental Engineering, Vol. 4, pp 176 - 181, 2014.

[12] Bradford, S. A. "Corrosion Control", Second Edition, Casti Publishing Inc, Alberta, Canada, 2001.

[13] Adey, R. A. Niku, S. M. and Brebbia, C. A. "Computer Aided Design of cathodic Protection system", Journal of Applied Ocean Research, Vol. 8, No 4, 1986.

[14] Agarwal, S., Kumar, S., Agarwal, M. and Kamal, M. "Corrosion: A General Review", Intena Onal Conference of Advance Research and Innova, 2015.

[15] Ezekiel, E. "Introduction to Electrical Design for Cathodic Protection Systems", Ezekiel Enterprises, LLC, Article's Review, 2015.

[16] Dwight, H. B. "Calculation of Resistance to Ground", Electrical Engineering, pp 1319 - 1329, 1936.

[17] Abdulamer, D. N. "Effect of Soil Resistivity for Different Geometry Anodes on Design Photovoltaic for Cathodic Protection", Journal of Global Research Analysis, Vol. 2, pp 2277 - 8160, 2013.

[18] M'hammed, O. Mourad, Z., Aicha, Z., Omar, T., Rachid, I., Saida, B. and Charif, D. "AC Corrosion Induced by High Voltage Powerline on Cathodically Protected Pipeline", International Conference on Control, Engineering and Information Technology-proceeding, IPCO, 2014.

[19] BS EN 13174, "Cathodic Protection for Harbour installation, 2001. 